\title{
Abatacept in the treatment of rheumatoid arthritis
}

\author{
Edward M Vital \\ Paul Emery \\ Academic Unit of Musculoskeletal \\ Disease, University of Leeds, Chapel \\ Allerton Hospital, Leeds, UK
}

\begin{abstract}
Abatacept (CTLA4-Ig) is a new agent which targets T-cell activation, an event which is thought to be critical to the onset and maintenance of rheumatoid arthritis (RA). Abatacept now has substantial evidence from phase III trials for efficacy in patients with RA who have failed to respond to disease-modifying antirheumatic drugs (DMARDs) and antitumor necrosis factor-alpha (TNF- $\alpha$ ) biologic agents. Safety profile is favorable in combination with DMARDs. The mechanism of action and available evidence of its efficacy and safety are reviewed in this article.
\end{abstract}

Keywords: abatacept, rheumatoid arthritis, disease-modifying antirheumatic drugs

\section{Introduction \\ Co-stimulation}

T-cell activity depends on activation. T-cell function depends on at least two signals. The first is provided by the binding of the T-cell receptor (TCR) to its cognate antigen. The second is provided by one or more co-stimulatory pathways. Binding of antigen in the absence of co-stimulation results not in activation but in anergy, a state where the cell is refractory to stimulation. Co-stimulatory pathways have been described for a number of cell types including memory and effector T-cells and B-Cells. Both positive and negative co-stimulatory pathways exist.

Of these many pathways, one of the most important, which is of therapeutic interest is that between CD80/86 on antigen-presenting cells and CD28 on naïve T-cells. This interaction is necessary for T-cell activation. CD28 signaling mediates expression of IL2 and anti-apoptotic molecules, amongst other effects (Jenkins et al 1991). Shortly after activation has occurred the T-cell then expresses a number of other co-stimulatory molecules including CTLA4, which is homologous to CD28 but binds CD80 and CD86 with higher affinity (Linsley et al 1991). CTLA4 expression therefore results in competitive inhibition of further binding with CD28, terminating T-cell activation. There is evidence that CTLA4 polymorphisms are associated with loss of selftolerance (Gough et al 2005) and therefore that CTLA4 may help to regulate immune responses to prevent autoimmune diseases.

\section{Rationale for co-stimulation blockade in rheumatoid arthritis}

There is accumulating evidence that T-cells are important in the pathogenesis of rheumatoid arthritis (RA). Transfer of T-cells from humans with RA to immunodeficient mice can induce the clinical features of RA (Mima et al 1995). A mouse model in which auto-reactive T-cells are selected, rather than deleted, in the thymus results in an RA-like phenotype (Sakaguchi et al 2003). T-cell differentiation is abnormal in RA, and abnormal T-cell phenotype correlates with disease severity (Ponchel et al 2002).
Correspondence: Paul Emery Academic Unit of Musculoskeletal Disease, University of Leeds, Chapel Allerton Hospital, Leeds, LS7 4SA, UK Tel +44 II 33924869

Email p.emery@leeds.ac.uk 
CD28 expression is increased in CD4+ cells from RA patients compared with controls, and the mean expression of CD28 is greatest for patients with clinically active disease (Salazar-Fontana et al 2001). There is therefore a good rationale for targeting CD28-mediated T-cell activation in RA.

\section{CTLA4-Ig}

Abatacept (CTLA4-Ig - Orencia ${ }^{\circledR}$, Bristol Myers Squibb, New York, USA) is a soluble fusion protein consisting of the extra-cellular domain of human CTLA4 and a fragment of the Fc portion of human IgG1 (hinge and $\mathrm{CH} 2$ and 3 domains). It binds human B7 (CD80/86) more strongly than CD28 (Linsley et al 1991).

\section{Pharmacokinetics}

Pharmacokinetics were studied in a phase I dose-finding clinical trial in patients with psoriasis. Patients were randomized to one of 8 dose levels: $0.5 \mathrm{mg} / \mathrm{kg}, 1 \mathrm{mg} / \mathrm{kg}$, $2 \mathrm{mg} / \mathrm{kg}, 4 \mathrm{mg} / \mathrm{kg}, 8 \mathrm{mg} / \mathrm{kg}, 16 \mathrm{mg} / \mathrm{kg}, 25 \mathrm{mg} / \mathrm{kg}$, and $50 \mathrm{mg} /$ $\mathrm{kg}$, and within this range abatacept exhibited linear pharmacokinetics with a mean serum half-life of 14.7 days. There was no change in half-life throughout the dose range. A later double-blind placebo-controlled study in RA which tested $0.5 \mathrm{mg} / \mathrm{kg}, 2 \mathrm{mg} / \mathrm{kg}$ and $10 \mathrm{mg} / \mathrm{kg}$ doses found optimum clinical response using the $10 \mathrm{mg} / \mathrm{kg}$ dose (Moreland et al 2002).

In vitro studies have shown a dose-dependent inhibition of T-cell proliferation by abatacept after stimulation by antigen-presenting cells (Symington et al 1993). When treated with abatacept $10 \mathrm{mg} / \mathrm{kg}$ on days $1,15,30$, and then every 30 days, minimum serum abatacept concentrations ranged from $28.7 \pm 3.8 \mu \mathrm{g} / \mathrm{ml}$ on day 60 and $22.0 \pm 1.7 \mu \mathrm{g} / \mathrm{ml}$ on day 180. Abatacept was able to inhibit T-cell proliferation in vitro at concentrations between $3.16 \mu \mathrm{g} / \mathrm{ml}$ and $100 \mu \mathrm{g} /$ $\mathrm{ml}$ (Nadler et al 2004)

\section{Immunological activity}

Analysis of multiple biomarkers from peripheral blood of patients in phase IIb, Abatacept in patients with an inadequate response to methotrexate (AIM) and Abatacept trial in treatment of anti-tumor necrosis factor inadequate responders (ATTAIN) trials (Weisman et al 2004; Emery, Westhovens, et al 2005) have shown reduction of a number of biomarkers including rheumatoid factor, C-reactive protein (CRP), soluble interleukin-2 (IL-2) receptor, interleukin-6 (IL-6), tumor necrosis factor-alpha (TNF- $\alpha$ ), E-Selectin, soluble intercellular adhesion molecule 1, and matrix metalloproteinase-3 (MMP-3). These changes are consistent with inhibition of both T-cell activation and a downstream effect on B-Cells and antigen-presenting cells.

Abatacept causes a near-complete inhibition of T-cell proliferation after stimulation by dendritic cells, but a lesser inhibition when the antigen-presenting cell is a BCell (Davis et al 2005). Blockade of the CD28/B7 pathway in vivo using CTLA4-Ig has also been shown to prevent expansion of memory T-cells after restimulation with antigen (Ndejembi et al 2005). No effect of abatacept on TNF- $\beta$ production by monocytes confirms that this drug spares innate immune responses (Davis et al 2005).

Synovial histology and gene expression have been examined in patients treated with abatacept after failure of anti-TNF- $\alpha$ therapy (Buch et al 2005). Synovial biopsies were examined by semi-quantitative immunohistochemistry and quantitative real-time polymerase chain reaction for synovial messenger ribonucleic acid (mRNA) expression at baseline and 4 months. There was a clinical response in $7 / 11$ patients. Although there was no change in total T-cell numbers, staining for CD4 decreased. Expression of mRNA for interferon- $\gamma$ (IFN- $\gamma$ ), TNF- $\alpha$, MMP-1, MMP-3, interleukin-1 (IL-1) and receptor activator of NF- $\mathrm{KB}$ (RANK) decreased by $20 \%-50 \%$ from baseline but there was very little change in IL-6. These findings indicate that the mechanism of action of abatacept involves local synovial suppression of a range of cytokines from both T-cells and macrophages.

\section{Immunogenicity}

Since it is a fully humanized protein, and is itself immunosuppressive, development of anti-abatacept antibodies would not be anticipated to be a common problem. The large scale trials on which immunogenicity data have been published both used abatacept in combination with methotrexate or another disease-modifying antirheumatic drug (DMARD). In the larger, phase III trial (Genovese, Becker, et al 2005) antibodies against abatacept developed in $1.3 \%$ of patients and were of low reactivity. An earlier trial (Kremer et al 2003) found no anti-abatacept antibody seroconversion in 220 treated patients.

\section{Efficacy \\ Studies of efficacy}

Despite recent advances in therapies for RA there remain a number of unmet needs for therapy (Moreland 2005). A 
subgroup of patients will respond to DMARD monotherapy. In others, combinations of DMARDs or TNF- $\alpha$-blockers are needed due to resistant disease activity or toxicity. There remain groups of patients for whom none of these treatments are satisfactory due to toxicity or resistance. For these reasons trials to date for abatacept have focused on: (1) demonstrating activity against RA; (2) Demonstrating efficacy for patients inadequately controlled by methotrexate or TNF- $\alpha$ blockers; (3) demonstrating a toxicity profile that is acceptable in general, and preferable to those of existing therapies for some sub groups.

Outcome measures used in these studies have included the American College of Rheumatology (ACR) response rates, which measure the proportion of patients with a $20 \%$, $50 \%$ or $70 \%$ improvement in number of tender and swollen joints from 68 assessed, as well as a $20 \%$ improvement in at least three of the following: the patient's global assessments of disease status, pain and physical function, physician's assessment of disease status, and the CRP level. The Disease Activity Score 28 (DAS28) is another validated measure of disease activity using similar variables of tender and swollen joint counts from a sample of 28, erythrocyte sedimentation rate (ESR) and patient's assessment of global health. The DAS28 yields a numeric value. Changes of less than 0.6 are considered to indicate non-response, and score of $\leq 2.4$ with improvement of at least 1.2 a good response. A DAS28 score of less than 2.6 indicates remission and correlates closely with the ACR criteria for remission.

The Modified Stanford Health Assessment Questionnaire (mHAQ) measures patient-centered outcomes of disability, pain, and global health. It focuses on physical function especially of the upper limb. Psychiatric and social outcomes are not assessed. The Medical Outcome Short Form (36) Health Survey (SF36) assesses less disease-specific dimensions of quality of life. The scale includes physical (physical function, limitations in role due to physical problems, bodily pain, and general health) and mental (vitality, social function, limitations in role due to emotional problems and mental health) components, as well as physical and mental summaries. Scores are in the range 0-100 for each domain. Lower scores indicate worse function, and an improvement of at least 3 points is considered clinically meaningful. Physical function components of the SF36 correlate closely with the mHAQ (Talamo et al 1997).

Activity against RA has been demonstrated in a phase I dose-ranging study (Moreland et al 2002). This study determined the dosing schedule that has become standard and has been used in all subsequent studies. Infusions of abatacept are given at day $1,15,30$ and then every 30 days as a 30-minute intravenous infusion. The optimum dose has been determined as $10 \mathrm{mg} / \mathrm{kg}$. Later studies have used a simplified dosing system using an approximation of body weight.

Efficacy in patients who have inadequately responded to methotrexate and other DMARDs has been assessed in a large phase IIb trial (Kremer et al 2003; Kremer, Dougados, et al 2005). A large phase III trial in a similar group of patients also includes radiographic data (AIM; Emery, Russell, et al 2005; Genant et al 2005; Kremer, Westhovens, et al 2005; Russell et al 2005). Another phase III trial assessed efficacy of abatacept in patients who have inadequately responded to TNF- $\alpha$-blockers, a group for whom there are currently few therapeutic options (Genovese, Becker, et al 2005). In addition to the safety data available from all of these trials, there has also been a separate large-scale study of safety in patients with a range of co-morbidities and concomitant therapies (Abatacept study of safety in use with other rheumatoid arthritis therapies [ASSURE] trial) (Weinblatt et al 2005).

\section{Studies in patients not responding to DMARDs}

Evidence for efficacy of abatacept in the group of patients not responding to methotrexate comes from two studies, which examine similar groups of patients. The first was a phase IIb study of patients who had failed at least $10 \mathrm{mg}$ / week of methotrexate for at least 6 months (Kremer et al 2003; Kremer, Dougados, et al 2005). Disease activity was high at baseline with all patients showing erosive change and $90 \%$ positive for rheumatoid factor. Patients were treated with either $2 \mathrm{mg} / \mathrm{kg}$ or $10 \mathrm{mg} / \mathrm{kg}$ of abatacept or placebo according to the standard schedule. Double blind therapy continued for 12 months and then patients in the $10 \mathrm{mg} / \mathrm{kg}$ could enter an open label long-term extension from which 3 year data are published. Primary endpoint was ACR20 at 6 months and secondary endpoints the other ACR responses and modified Health Assessment Questionnaire (mHAQ) and Short-Form 36 Quality of Life Questionnaire (SF36) at 6 and 12 months. Although there was evidence of efficacy at the $2 \mathrm{mg} / \mathrm{kg}$ dose, results were inferior to those at $10 \mathrm{mg} /$ $\mathrm{kg}$ with no significant difference in side-effect profile and so later studies have used a $10 \mathrm{mg} / \mathrm{kg}$ dose only.

The second study (AIM) recruited patients who had failed at least $15 \mathrm{mg} /$ week of methotrexate for at least 3 months and randomized to either abatacept $10 \mathrm{mg} / \mathrm{kg}$ or 
placebo. Double-blind therapy continued for 12 months. The most important difference from the earlier phase IIb study was that the AIM study included a radiographic endpoint. Genant-modified Sharp Score, ACR20 and mHAQ response were all primary endpoints. Other ACR responses, DAS28 and SF36 at 6 and 12 months were secondary endpoints.

\section{Disease activity}

Data from double-blind follow up of patients in both the phase IIb and phase III AIM studies has been published in abstract form for 6 and 12 months endpoints. These are summarized in Figures 1 and 2. These rates of response are high for patients who have been resistant to methotrexate, and comparable to those achieved with anti-TNF- $\alpha$ agents. A separate analysis of individual ACR components shows improvements across all components for the phase IIb study (see Table 1).

A separate analysis of data from the phase IIb study has shown that improvements in disease activity, pain and physical function occurred by 30 days (Emery et al 2004). The proportion of patients achieving a 50\% improvement in the pain visual analog scale (VAS), mHAQ, and ACR50 were compared between treatment arms at time-points from 15 to 360 days. Visual analogue scales for disease activity and pain were significantly better in the abatacept group by 15 days. ACR and mHAQ results are shown in Figures 3 and 4.
Some patients from the $10 \mathrm{mg} / \mathrm{kg}$ arm of the phase $\mathrm{IIb}$ study entered an open-label extension for a further year. Sustained efficacy was shown in patients who completed 2 years of treatment (Kremer et al 2004). Responses in patients who completed follow up were sustained. These results must be interpreted with some caution however as only 84 of the original 115 patients randomized to abatacept $10 \mathrm{mg} / \mathrm{kg}$ entered the extension, and of these only 74 completed 2 years of follow up. In data from the AIM trial there is a tendency towards increasing responses between months 6 and 12 , and it may be that there is cumulative improvement in disease activity.

By post-hoc comparison of subgroups, ACR response rates have been compared according to baseline mHAQ and disease duration (Russell et al 2004; Kremer, Westhovens, et al 2005). ACR response rates were independent of baseline mHAQ and disease duration.

\section{Structural change}

The phase III AIM trial is the only study of abatacept to include a radiographic endpoint. Since it is thought to inhibit a number of downstream inflammatory pathways it would be expected to indirectly reduce structural changes in a similar fashion to DMARD and anti-TNF- $\alpha$ agents.

Paired radiographs at baseline and 12 months were obtained from $92 \%$ of all randomized patients in the AIM study. They were scored by 2 assessors, blinded for treatment group and chronological order, using the Genant-modified

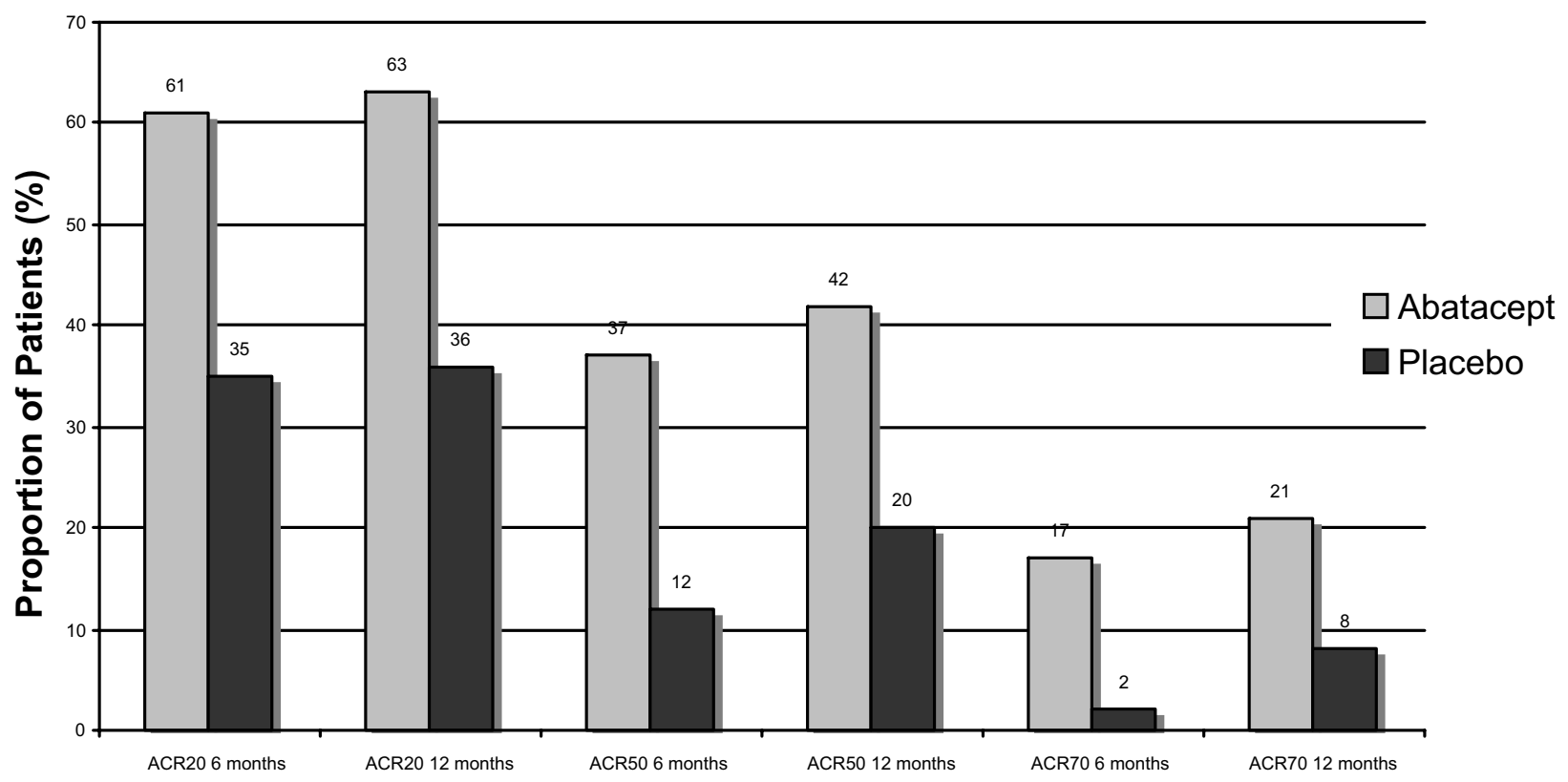

Figure I ACR responses at 6 and 12 months in the phase Ilb trial of abatacept versus placebo.

Abbreviations: ACR, American College of Rheumatology. 


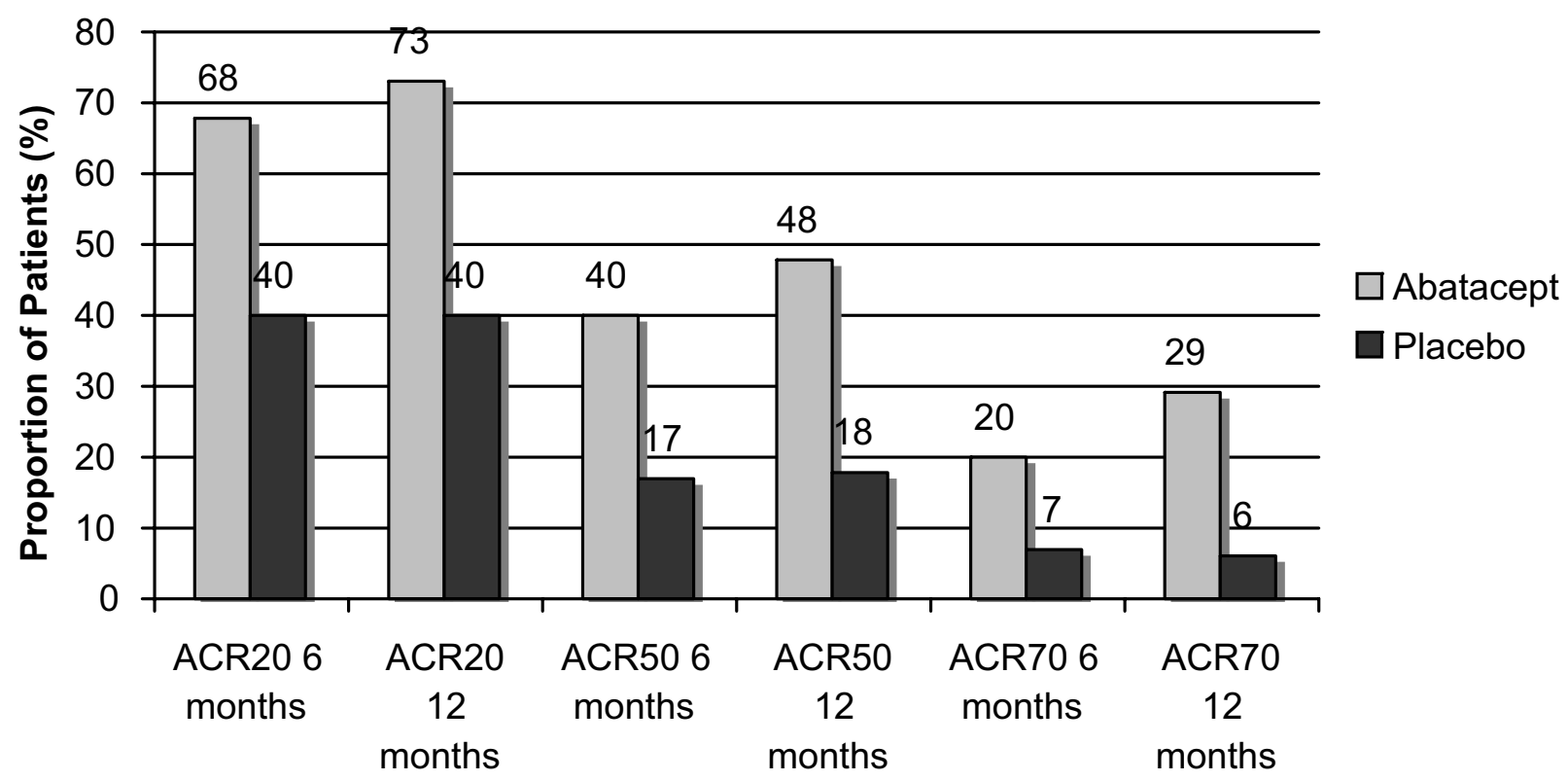

Figure 2 ACR Responses at 6 and 12 months in the AIM study.

Abbreviations: AIM, Abatacept in patients with an inadequate response to methotrexate; ACR, American College of Rheumatology.

Sharp Score. This includes scores for erosion and joint space narrowing, each between 0 and 145 and a total score between 0 and 290. Median changes in these scores at 12 months have been published in abstract form (Genant et al 2005) and are shown in Table 2. A comparison of patients with and without an ACR20 response was made using mean change in Genant-modified-Sharp Score from baseline. Although this is not usually considered the best measure for comparing non-parametrically distributed data such as radiographic scores, there was a significant difference between means between abatacept and treatment groups for ACR20 responders and non-responders for erosions, joint space narrowing, and total scores. These data suggest that patients whose disease activity did not respond may still benefit from retardation of structural damage. Patients who had an ACR response on placebo and methotrexate did not show the same retardation of structural change as patients on abatacept and placebo.

\section{Function and quality of life}

Results of mHAQ and SF36 have been published at 6 and 12 months for patients in the double-blind phase of the phase IIb trial (Kremer et al 2003; Kremer, Dougados, et al 2005). In addition, 2 and 3 year data have been published for the 84 abatacept-treated patients who entered the open-label long term extension (Emery, Russell, et al 2005).

Table I AIM trial: improvements in measures of disease activity at 6 and 12 months

\begin{tabular}{|c|c|c|c|c|c|}
\hline & & \multicolumn{2}{|l|}{6 months } & \multicolumn{2}{|l|}{12 months } \\
\hline & & $\begin{array}{l}\text { Abatacept } \\
(n=2 \mid 4)\end{array}$ & $\begin{array}{l}\text { Placebo } \\
(n=424)\end{array}$ & $\begin{array}{l}\text { Abatacept } \\
(n=2 \mid 4)\end{array}$ & $\begin{array}{l}\text { Placebo } \\
(n=424)\end{array}$ \\
\hline \multirow[t]{4}{*}{$\%$ Patients } & ACR20 & $68^{*}$ & 40 & $73^{*}$ & 40 \\
\hline & ACR50 & $40^{*}$ & 17 & $48^{*}$ & 18 \\
\hline & ACR70 & $20 *$ & 7 & $29 *$ & 6 \\
\hline & DAS remission & $14.8 *$ & 2.8 & $23.8^{*}$ & 1.9 \\
\hline Mean \% improvement & Tender joints & $62.6 *$ & 40.7 & $68.8^{*}$ & 42.1 \\
\hline \multirow[t]{5}{*}{ from baseline } & Swollen joints & $65.0 *$ & 39.5 & $70.5^{*}$ & 42.4 \\
\hline & Pain & $42.5^{*}$ & 3.5 & $50.5^{*}$ & 8.0 \\
\hline & Patient globalVAS & $42.0 *$ & 13.7 & $48.3^{*}$ & 19.6 \\
\hline & Physician globalVAS & $62.2^{*}$ & 36.5 & $68.0 *$ & 37.9 \\
\hline & CRP & $24.3^{*}$ & -19.3 & $29.2 *$ & -22.7 \\
\hline
\end{tabular}

Note: ${ }^{*} \mathrm{p}<0.001$ versus placebo.

Abbreviations: ACR, American College of Rheumatology; AIM, Abatacept in patients with an inadequate response to methotrexate; CRP, C-reactive protein; DAS, disease activity scores;VAS, visual analog scale. 
Improvement in mHAQ from baseline was already greater in abatacept-treated patients by 30 days as previously mentioned. This response had further increased at 6 months $(58.3 \%$ with $10 \mathrm{mg} / \mathrm{kg}$ abatacept + methotrexate (MTX) vs $33.6 \%$ with placebo+MTX, $\mathrm{p}<0.001)$. At one year, by intention to treat analysis, this appeared to have dropped slightly ( $42.3 \%$ with $10 \mathrm{mg} / \mathrm{kg}$ abatacept plus MTX vs $10.3 \%$ with placebo plus MTX, $\mathrm{p}<0.001$ ), but the authors report that analysis by last-observation carried forward did not show a reduction of mHAQ between 6 and 12 months. The sustained response in mHAQ for patients who entered the long-term extension up to 3 years would support this. In these patients mean percentage improvement in $\mathrm{mHAQ}$ from baseline at 12, 24, and 36 months was 49.4, 46.3, and 49.3 respectively. All domains and summary scores of the SF36 had improved at 6 months for patients treated with $10 \mathrm{mg} /$ $\mathrm{kg}$ abatacept compared with placebo. Physical and mental component scores have been published for the long term extension and again in these patients these responses were sustained.

Results for response in mHAQ, SF36 physical and mental component summary scores, medical outcomes study sleep module have been published for the AIM study at 6 and 12 months and are summarized in Table 3. These results confirm that improvements in disease activity in patients treated with abatacept translate into improvements in a variety of patient-centred outcomes.

\section{Studies in patients not responding to anti-TNF- $\alpha$ agents}

Since abatacept has a different mechanism of action, it would be expected that patients who have failed one or more antiTNF- $\alpha$ agents may still respond to abatacept. Typically this group of patients has few or no other therapeutic options, as most will have failed to respond to a large number of

Table 2 Genant-modified Sharp Score: median change from baseline at 12 months in the AIM trial

\begin{tabular}{llll}
\hline & $\begin{array}{l}\text { Median change from baseline (25th, 75th } \\
\text { percentile) }\end{array}$ & & \\
\cline { 2 - 4 } & $\begin{array}{l}\text { Abatacept-MTX } \\
(\mathbf{n}=424)\end{array}$ & $\begin{array}{l}\text { Placebo-MTX } \\
(\mathbf{n}=\mathbf{2} \text { 14) }\end{array}$ & $\begin{array}{l}\text { p (abatacept } \\
\text { vs placebo) }\end{array}$ \\
\hline $\begin{array}{l}\text { Erosion score } \\
\text { Joint space }\end{array}$ & $0.00(0.00,1.02)$ & $0.27(0.00,1.27)$ & 0.029 \\
narrowing & $0.00(0.00,0.49)$ & $0.00(0.00,0.97)$ & 0.009 \\
Total score & $0.25(0.00,1.78)$ & $0.53(0.00,2.54)$ & 0.012 \\
\hline
\end{tabular}

Abbreviations: AIM, Abatacept in patients with an inadequate response to methotrexate; MTX, methotrexate.
Table 3 Function and quality of life outcome assessments at 6 and 12 months from the AIM trial

\begin{tabular}{lllll}
\hline & \multicolumn{2}{l}{$\mathbf{6}$ months } & \multicolumn{3}{l}{ 12 months } \\
\cline { 2 - 5 } & Abatacept & Placebo & Abatacept & Placebo \\
\hline $\begin{array}{l}\text { mHAQ \% } \\
\text { improvement } \\
\text { mHAQ }\end{array}$ & 35.2 & 20.9 & 37.3 & 19.6 \\
$\begin{array}{l}\text { response rate } \\
\begin{array}{l}\text { SF36 MCS } \\
\text { (mean improvement } \\
\text { from baseline) }\end{array}\end{array}$ & 61.1 & 45.3 & 63.7 & 39.3 \\
$\begin{array}{l}\text { SF36 PCS } \\
\text { (mean improvement } \\
\text { from baseline) }\end{array}$ & 8.8 & 3.8 & 6.9 & 4.7 \\
$\begin{array}{l}\text { MOS-sleep } \\
\text { (mean improvement } \\
\text { from baseline) }\end{array}$ & -10.2 & 4.8 & 9.1 & 5.0 \\
\hline
\end{tabular}

Abbreviations: AIM, Abatacept in patients with an inadequate response to methotrexate; MCS, Short Form 36 Mental Component Summary; mHAQ, Modified Stanford Health Assessment Questionnaire, MOS, Sleep, Medical Outcomes Study Sleep Module; PCS, Short Form 36 Physical Component Summary.

DMARDs already. For this reason, they also have disease of longer duration than the other abatacept studies.

In the phase III ATTAIN trial (Genovese, Becker, et al 2005), patients had discontinued at least 3 months treatment with anti-TNF- $\alpha$ agents because of lack of efficacy or still had active disease despite anti-TNF- $\alpha$, as defined by joint counts and CRP. Patients who were unable to tolerate, or had contraindications to, anti-TNF- $\alpha$ were therefore not recruited. One stable dose background DMARD was continued throughout the study. Concurrent therapy could include any oral DMARD or anakinra (IL-1 receptor antagonist), and in the majority of patients (78\%) was methotrexate. Stable low dose nonsteroidal antiinflammatory drugs (NSAIDs) and corticosteroids were also continued.

258 patients were randomized to abatacept and 133 to placebo. Baseline characteristics were similar between these two groups with high disease activity. Mean tender joint count was greater than 30 and swollen joint count greater than 20 for each group, with mean DAS28 of $6.5 \pm 0.9$ for the abatacept group and $6.5 \pm 0.8$ for placebo.

Treatment schedules were the same as in earlier studies using a $10 \mathrm{mg} / \mathrm{kg}$ dose. There were two primary endpoints: the proportion of patients achieving an ACR20 response, and proportion with an improvement of $\geq 0.3$ in mHAQ. Secondary endpoints included ACR50 and 70 response rates, improvements in DAS28, and improvement in SF36. 


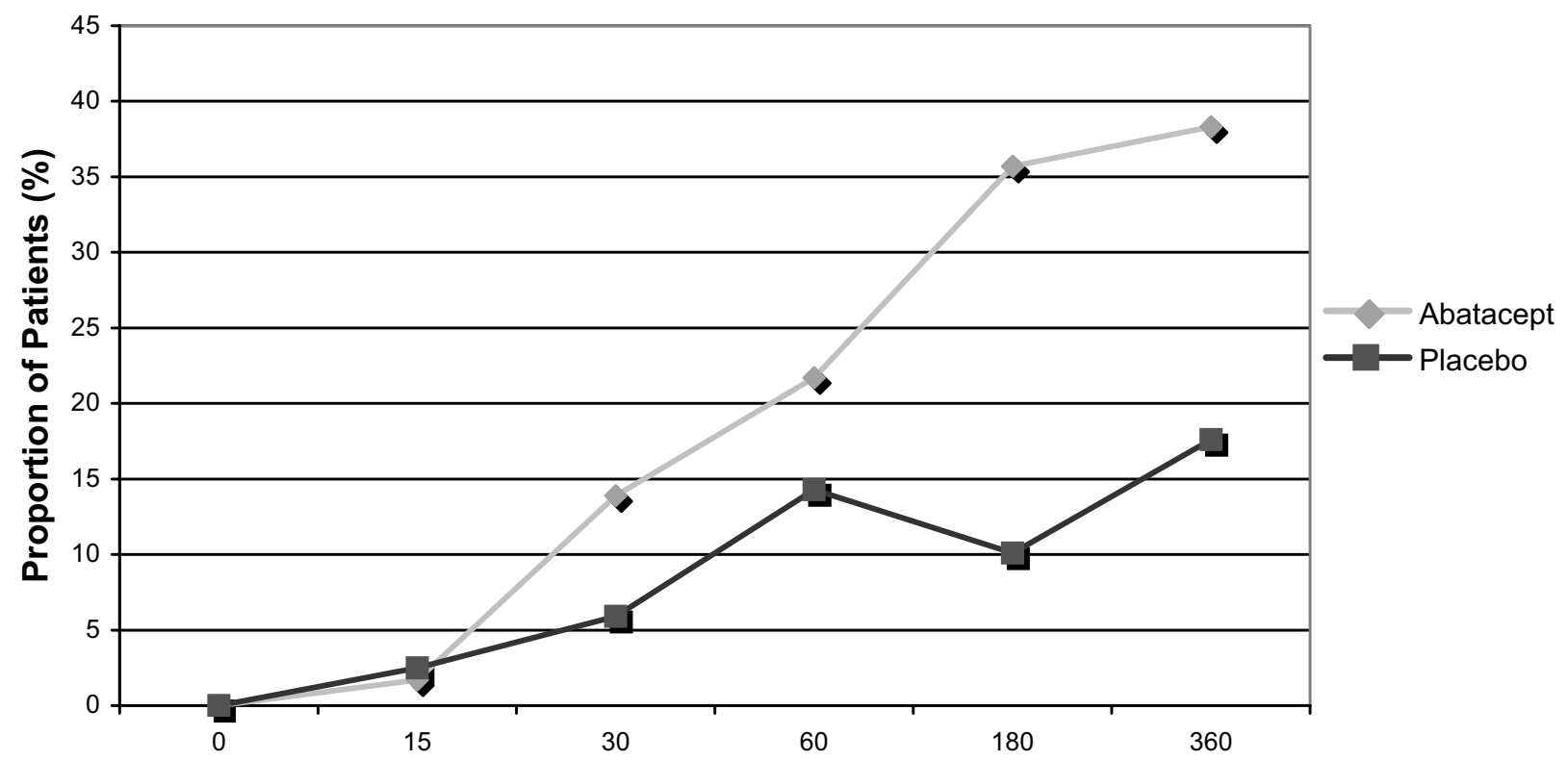

Figure 3 Percentage of patients achieving an ACR50 response on abatacept $10 \mathrm{mg} / \mathrm{kg}$-methotrexate or placebo-methotrexate.

Abbreviations: ACR, American College of Rheumatology.

\section{Disease activity and function}

There were significant improvements in all of the primary and secondary endpoints at six months. Data for improvements in the components of the ACR and DAS28 response have been published separately. These data are summarized in Figure 5 and Table 4. These response rates

Table 4 Improvements in disease activity measures at 6 months in the ATTAIN trial. ACR individual components: (Schiff et al 2005); DAS components: (Dougados et al 2005)

\begin{tabular}{llll}
\hline & $\begin{array}{l}\text { Abatacept } \\
(\mathbf{n = 2 5 6 )}\end{array}$ & $\begin{array}{l}\text { Placebo } \\
(\mathbf{n = 1 3 3 )}\end{array}$ & $\mathbf{p}$ \\
\hline ACR20 (\% patients) & 50.4 & 19.5 & $<0.00$ I \\
ACR50 (\% patients) & 20.1 & 3.8 & $<0.00$ I \\
ACR70 (\% patients) & 10.2 & 1.5 & 0.003 \\
$\begin{array}{l}\text { Tender Joint Count } \\
\text { (mean \% improvement) }\end{array}$ & 47.8 & 20.0 & $<0.01$ \\
$\begin{array}{l}\text { Swollen Joint Count } \\
\text { (mean \% improvement) }\end{array}$ & 44.3 & 23.8 & $<0.01$ \\
$\begin{array}{l}\text { Patient-reported pain } \\
\text { (mean \% improvement) }\end{array}$ & 28.6 & 4.4 & $<0.001$ \\
$\begin{array}{l}\text { Patient global assessment } \\
\text { (mean \% improvement) }\end{array}$ & 30.9 & 4.5 & $<0.01$ \\
$\begin{array}{l}\text { Physician global assessment } \\
\text { (mean \% improvement) }\end{array}$ & 45.2 & 21.3 & $<0.01$ \\
$\begin{array}{l}\text { CRP (mean \% improvement) } \\
\text { DAS Response }\end{array}$ & 25.1 & -28.4 & $<0.01$ \\
$\begin{array}{l}\text { DAS low disease activity } \\
\text { DAS Remission }\end{array}$ & 17.1 & 3.1 & $<0.00$ I \\
\hline
\end{tabular}

Abbreviations: ACR, American College of Rheumatology, ATTAIN, Abatacept trial in treatment of anti-tumor necrosis factor inadequate responders; CRP, Creactive protein; DAS, disease activity scores. are impressive for such a resistant group of patients, including an ACR20 rate of 50.4\% and a DAS28 remission rate of $10.0 \%$. mHAQ improved in $47.3 \%$ of patients in the abatacept arm compared with $23.3 \%$ on placebo. Mean mHAQ disability index improvement from baseline was 0.45 for abatacept compared with 0.11 for placebo. Of 34 discontinuations in the placebo arm, 27 were due to lack of efficacy and 5 due to adverse events. In the abatacept arm, 14 discontinued due to lack of efficacy and 9 due to adverse events.

Although comparisons of efficacy between different trials are often problematic, it is interesting to note that the ACR response rate for highly resistant patients with longer disease duration, who have failed both DMARDs and antiTNF agents, are approaching those in the phase IIb trial for patients who have failed DMARDs only. This suggests that the mechanism of resistance of anti-TNF is independent from determinants of response to abatacept. This would be consistent with the hypothesis that abatacept inhibits disease activity in RA by mechanisms other than a downstream effect on TNF.

\section{Function and quality of life}

It is important to confirm that improvements in disease activity correlate with perceived health improvements in patients with longstanding advanced RA and high baseline mHAQ. A wide range of quality of life measures have been reported from the ATTAIN patients including the SF36 individual and summary scores, number of days in which 


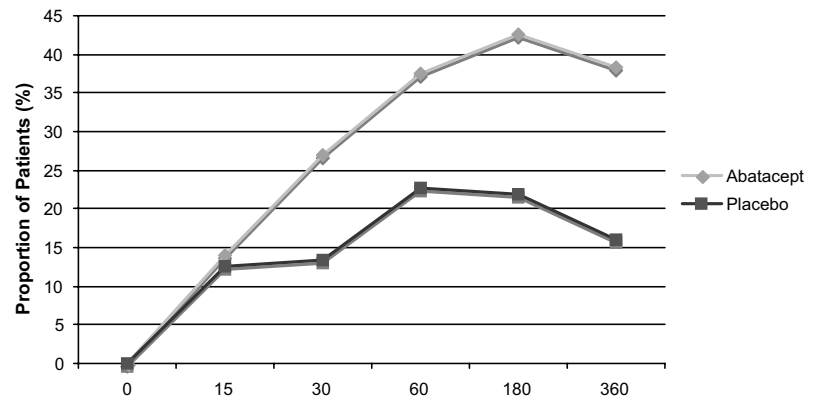

Figure 4 Percentage of patients achieving $50 \%$ improvement in mHAQ from baseline on abatacept $10 \mathrm{mg} / \mathrm{kg}$-methotrexate or placebo-methotrexate. Abbreviations: mHAQ, Modified Stanford Health Assessment Questionnaire.

patients were unable to perform activities of daily living, visual analog scales for pain and fatigue, and the medical outcomes study sleep module. The quality of life data are summarized in Table 5.

\section{Subgroups of previous anti-TNF- $\alpha$ therapies}

Analyses of subgroups based on previous anti-TNF therapies have also been published. Effects of anti-TNF that was current or prior at the time of enrollment were examined. Patients who were treated with anti-TNF- $\alpha$ agents at recruitment had to have a 28-60 day washout period (depending on type of previous therapy) before randomization. This may have induced an artificial disease flare that could account for the high baseline disease activity and could potentially also lead to a high placebo response rate. To exclude this possibility, CRP and joint counts were compared at screening and randomization and found no significant increase during washout. Patients were stratified by prior or current therapy within each treatment arm. A separate analysis compared baseline disease activity and 6 month ACR20 and mHAQ responses for the group who had discontinued anti-TNF- $\alpha$ agents in the past or who were still using anti-TNF- $\alpha$ before a washout (Genovese, Schiff, et al 2005). These endpoints were met for both groups, with small differences (ACR20 45.4\% for washout and 53.3\% for prior therapy; mHAQ response $43.3 \%$ for washout and $49.4 \%$ for prior therapy). Placebo ACR response was higher in the prior therapy group (23.1\% vs $14.5 \%)$. The absence of disease flares in the washout group excludes the possibility that deterioration after withdrawal of anti-TNF$\alpha$ was responsible for the difference between treatment arms.

The type of anti-TNF therapy was also compared, which in the majority of patients was etanercept, infliximab or both, since adalimumab was not in such widespread use at the time of enrollment. Clinical benefit was observed for all these groups. There was a tendency towards greater improvement for patients previously treated with infliximab in the abatacept group but not placebo.

\section{Safety}

Safety of abatacept has been assessed by data from the double-blind placebo controlled trials, and also a large-scale phase III trial which had safety as its endpoint (Weinblatt et al 2005). In view of its mode of action in suppressing T-cell

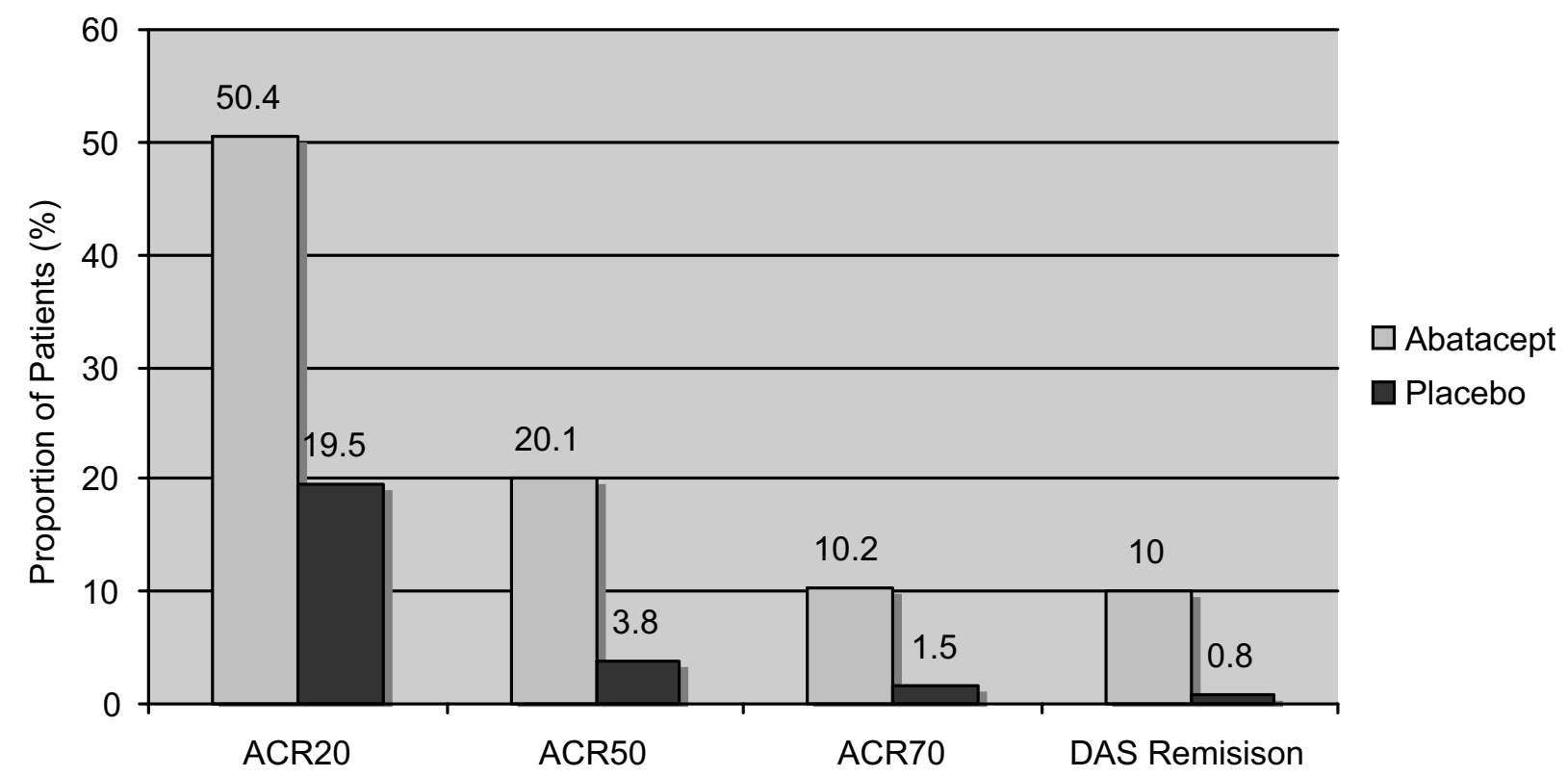

Figure 5 ACR improvements in disease activity in the ATTAIN trial at 6 months.

Abbreviations: ACR, American College of Rheumatology; ATTAIN, Abatacept trial in treatment of anti-tumor necrosis factor inadequate responders; DAS, disease activity scores. 
Table 5 Quality of life outcomes from the ATTAIN trial

\begin{tabular}{llll}
\hline & $\begin{array}{l}\text { Abatacept } \\
\text { (mean change } \\
\text { from baseline) }\end{array}$ & $\begin{array}{l}\text { Placebo } \\
\text { (Mean change } \\
\text { from baseline) }\end{array}$ & $\begin{array}{l}\text { (abatacept } \\
\text { vs placebo) }\end{array}$ \\
\hline Physical function & 5.3 & 1.3 & $<0.001$ \\
Physical role & 6.5 & 1.3 & $<0.001$ \\
Pain & 8.7 & 2.5 & $<0.001$ \\
General health & 4.0 & 0.7 & $<0.001$ \\
Vitality & 6.6 & 1.8 & $<0.001$ \\
Social function & 7.3 & 2.4 & $<0.001$ \\
Emotional role & 6.0 & 2.5 & $<0.05$ \\
Mental health & 4.3 & 1.6 & $<0.01$ \\
Physical & 6.6 & 1.1 & $<0.001$ \\
component & & & \\
summary & & & $<0.005$ \\
Mental & 5.2 & 2.1 & $<0.001$ \\
component & & & $<0.001$ \\
summary & & -7.9 & $<0.001$ \\
Pain VAS & -27.1 & -6.0 & $<0.001$ \\
FatigueVAS & -21.9 & & \\
MOS Sleep & & -2.8 & \\
Problems index & -9.4 & -1.87 & \\
No. days unable & -7.02 & & \\
to perform activities & & & \\
of daily living & & & \\
\hline
\end{tabular}

Note: For SF36 characteristics values represent mean decrease from baseline. A $\geq 3$ point decrease would be regarded as clinically meaningful. For VAS, days unable to perform activites of daily living, and MOS Sleep problems index a negative value indicates an improvement.

Abbreviations: ATTAIN, Abatacept trial in treatment of anti-tumor necrosis factor inadequate responders; MOS, Sleep, Medical Outcomes Study Sleep Module; VAS visual analog scale.

function and prior experience with other biological agents, incidence of infection and malignancy have been the focus of most concern in safety. Another area of concern is the potential induction of autoimmunity. Experience with antiTNF- $\alpha$ agents has shown that there is potential for unpredictable changes in the immune state when using targeted therapies. Regulatory T-cells $\left(\mathrm{T}_{\text {reg }}\right)$ have been shown to have a role in preventing autoimmune disease and to have altered function in active RA (Ehrenstein et al 2004). Since $\mathrm{T}_{\text {reg }}$ development and function is dependent on CTLA4 signaling (Tang et al 2004), another area of concern was that CTLA4-Ig could interfere with their function and affect tolerance to other auto-antigens. Lastly, any protein-based biologic agent administered intravenously has the potential to cause infusion reaction. Although this is less likely for a fully humanized molecule, this adverse event has been monitored closely.

In the ATTAIN trial (Genovese, Becker, et al 2005) between the abatacept and placebo groups there were similar rates of discontinuation due to serious adverse events and adverse events (3.5\% and 3.8\%, respectively and $2.7 \%$ and
$1.5 \%$, respectively), serious adverse events $(10.5 \%$ and $11.3 \%$, respectively) and total adverse events $(79.5 \%$ and $71.4 \%$, respectively).

Although there was no increase in serious infections, or in discontinuations due to infection, in the abatacept group, total infection rate was increased $(37.6 \%$ compared with $32.3 \%$ for placebo). These were common infections such as nasopharyngitis and bronchitis. There was concern that opportunistic infections similar to those seen in AIDS may occur because of abatacept's T-cell specific action, but this was not substantiated. There was no report of malignancy in the frequent $(>5 \%)$ adverse events of this study.

Anti-nuclear antibodies were measured at baseline and throughout the treatment phase. $7.5 \%$ of patients in the abatacept group and $11.3 \%$ in the placebo group became positive during the study. Development of anti-doublestranded DNA antibodies was more frequent in the placebo arm $(9.4 \%$ vs $1.7 \%$ for abatacept). Clinical features of autoimmune disease other than RA were not reported as a frequent $(>5 \%)$ adverse event.

There were no severe infusion reactions, but mild to moderate infusion reactions were increased in patients receiving abatacept (5.0\% vs 3.0\% for placebo). Headache and dizziness were the most common symptoms.

In the phase IIb trial (Kremer et al 2003) serious adverse events were more frequent in the placebo arm and discontinuation rates due to adverse events were lower in abatacept-treated patients. Most frequently reported adverse events were similar to those in the ATTAIN study. Safety data are not yet available from the AIM study.

\section{Safety with other therapies and co- morbidities}

The Abatacept study of safety in use with other rheumatoid arthritis therapies (ASSURE) was a double-blind placebo controlled trial with safety as its endpoint. Preliminary 1year data have been published in abstract form (Weinblatt et al 2005). Patients with a wide range of co-morbidities were recruited including diabetes mellitus (7\%), asthma (6\%), chronic obstructive pulmonary disease (COPD) (4\%), and congestive heart failure (1\%). Treatment was with standard dose abatacept or placebo in combination with oral DMARDs, anti-TNF- $\alpha$ or anti-IL1 biologic agents. A total of 1441 patients were randomized. The main findings are summarized in Table 6.

The data for abatacept in combination with non-biologic DMARD are similar to those from other trials, and are generally reassuring. Patients with COPD experienced more 
Table 6 Summary safety data from ASSURE at I year

\begin{tabular}{|c|c|c|c|c|}
\hline Event (\%) & $\begin{array}{l}\text { Abatacept + } \\
\text { non-biological } \\
\text { DMARD } \\
n=856\end{array}$ & $\begin{array}{l}\text { Placebo + } \\
\text { non-biological } \\
\text { DMARD } \\
n=418\end{array}$ & $\begin{array}{l}\text { Abatacept + } \\
\text { biological } \\
\text { DMARD } \\
n=103\end{array}$ & $\begin{array}{l}\text { Placebo + } \\
\text { biological } \\
\text { DMARD } \\
n=64\end{array}$ \\
\hline Total adverse events & 89.7 & 86.1 & 98 & 57 \\
\hline Discontinuations due to adverse events & 5.0 & 4.3 & 8.7 & 3.1 \\
\hline Death & 0.6 & 1.0 & 0 & 0 \\
\hline Serious adverse events & 11.7 & 12.2 & 22.3 & 12.5 \\
\hline Neoplasm (benign/malignant) & 3.2 & 3.8 & 6.8 & 1.6 \\
\hline Infection (pre-specified) & 3.2 & 3.8 & 6.8 & 1.6 \\
\hline Serious infection (pre-specified) & 1.5 & 1.0 & 3.9 & 1.6 \\
\hline
\end{tabular}

Abbreviations: ASSURE, Abatacept study of safety in use with other rheumatoid arthritis therapies; DMARD, disease-modifying antirheumatic drug.

frequent exacerbations on abatacept. At the time of writing details of rates individual infections and malignancies that are frequently problematic in RA and immunosuppressed patients had not been not published.

Abatacept in combination with biological agents does not appear to be safe, with increased incidence of serious infection and neoplasm. This combination is not recommended.

\section{Conclusions}

There is now substantial evidence that abatacept is a safe and effective drug for the treatment of established RA. Its initial role is likely to be as an alternative to antiTNF- $\alpha$ agents for patients who fail to respond or have a contraindication such as overlap with connective tissue disease. Abatacept may however have other properties. Since T-cells are thought to be involved in the initiation of RA, there is a good rationale for using abatacept in very early arthritis. It is possible that remission induced at this stage by co-stimulation blockade could be sustained without continuing treatment, and it will be interesting to see results of abatacept trials in early arthritis. In a rat model, prophylactic abatacept was found to prevent the onset of collagen-induced arthritis (Townsend et al 2005). Other T-cell mediated diseases are also to be investigated. There has been recent evidence for the use of abatacept in lupus (Davidson et al 2005) and the use of another related co-stimulation-blocking agent, belatacept (which also binds to CD80/86 but with higher affinity than abatacept), in renal transplantation (Vincenti et al 2005).

The use of abatacept in RA will become the first clinical application of the therapeutic approach of co-stimulation blockade that has the potential to fulfill a unique role in a wide variety of immunological problems.

\section{References}

Buch M, Boyle D, Saleem B, et al. 2005. The selective co-stimulation modulator abatacept decreases synovial inflammation and expression of pro-inflammatory cytokines in patients with rheumatoid arthritis. Arthritis Rheum, 52(Suppl):S446.

Davis PM, Nadler SG, Suchard SJ, et al. 2005. Abatacept differentially modulates human B-cell and dendritic cell stimulated T-cell effector function. Ann Rheum Dis, 64(Suppl III):128.

Davidson A, Diamond B, Wofsy D, et al. 2005. Block and tackle: CTLA4Ig takes on lupus. Lupus, 14:197-203.

Dougados M, Sherrer Y, Carrabba M, et al. 2005. Abatacept provides significant and clinically meaningful efficacy in rheumatoid arthritis patients with inadequate responses to anti-TNF therapy: disease activity score 28 assessments in the ATTAIN trial. Ann Rheum Dis, 64(Suppl III):458.

Ehrenstein MR, Evans JG, Singh A, et al. 2004. Compromised function of regulatory $\mathrm{T}$ cells in rheumatoid arthritis and reversal by antiTNFalpha therapy. J Exp Med, 200:277-85

Emery P, Combe B, Nuamah I, et al. 2004. Patients with rheumatoid arthritis treated with abatacept (CTLA4Ig; BMS-188667) report rapid improvements in pain, disease activity and physical function. Ann Rheum Dis, 63(Suppl I):525

Emery P, Russell A, Tate G, et al. 2005. Abatacept induces sustained improvements in health-related quality of life, sleep quality and fatigue over 3 years in rheumatoid arthritis patients with inadequate methotrexate responses. Ann Rheum Dis, 64(Suppl III):403.

Emery P, Westhovens R, Leon G, et al. 2005. Benficial effects of the selective co-stimulation modulator abatacept on biomarkers of rheumatoid arthritis immunopathology in patients with an inadequate response to methotrexate or TNF-inhibitor treatment. Ann Rheum Dis, 64(Suppl III):432.

Genant H, Peterfy C, Paira S. 2005. Abatacept significantly inhibits structural damage progression as assessed by the genant-modified sharp scoring system in rheumatoid arthritis patients with inadequate response to methotrexate. Ann Rheum Dis, 64(Suppl III):56.

Genovese M, Schiff M, Luggen M et al. 2005. Efficacy of Abatacept following wash-out of anti-TNF therapy in rheumatoid arthritis patients in the ATTAIN (Abatacept Trial in Treatment of Anti-TNF Inadequate Responders) Trial: current versus prior discontinuation. Arthritis Rheum, 52: S560-1

Genovese MC, Becker JC, Schiff M, et al. 2005. Abatacept for Rheumatoid Arthritis refractory to tumour necrosis factor a inhibition. $N$ Engl $J$ Med, 353:1114-23.

Gough SCL, Walker LSK, Sansom DM. 2005. CTLA4 gene polymorphism and autoimmunity. Immunol Rev, 204:102-15.

Jenkins MK, Taylor PS, Norton SD, et al. 1991. CD28 delivers a costimulatory signal involved in antigen-specific IL-2 production by human T cells. J Immunol, 147:2461-6. 
Kremer JM, Westhovens R, Leon M, et al. 2003. Treatment of rheumatoid arthritis by selective inhibition of T-cell activation with fusion protein CTLA4Ig. N Engl J Med, 349:1907-15.

Kremer JM, Westhovens R, Abud-Mendoza C, et al. 2005. Abatacept improves American College of Rheumatology responses and disease activity score 28 remission rates in both recent-onset and more established rheumatoid arthritis: results from the AIM trial. Arthritis Rheum, 52:S562-3.

Kremer J, Shergy W, Tindall E, et al. 2004. Sustained clinical efficacy demonstrated by the selective co-stimulation modulator abatacept (CTLA4Ig) in combination with methotrexate at 2 years in rheumatoid arthritis patients with an inadequate response to methotrexate. Arthritis Rheum, 50:S182,

Kremer JM, Dougados M, Emery P, et al. 2005. Treatment of rheumatoid arthritis with the selective costimulation modulator abatacept - twelvemonth results of a phase IIb, double-blind, randomized, placebocontrolled trial. Arthritis Rheum, 52:2263-71.

Linsley PS, Brady W, Urnes M. 1991. CTLA-4 is a second receptor for the B cell activation antigen B7. J Exp Med, 174:561-9

Mima T, Saeki Y, Ohshima S, et al. 1995. Transfer of rheumatoid arthritis into severe combined immunodeficient mice. The pathogenetic implications of $\mathrm{T}$ cell populations oligoclonally expanding in the rheumatoid joints. $J$ Clin Invest, 96:1746-58.

Moreland LW, Alten R, Van den Bosch F, et al. 2002. Costimulatory blockade in patients with rheumatoid arthritis: a pilot, dose-finding, double-blind, placebo-controlled clinical trial evaluating CTLA-4Ig and LEA29Y eighty-five days after the first infusion. Arthritis Rheum, 46:1470-9.

Moreland L. 2005. Unmet needs in rheumatoid arthritis. Arthritis Res Ther, 7(Suppl 3):S2-8.

Nadler S, Townsend R, Mikesell G, et al. 2004. Abatacept (CTLA4-IG; BMS-188667) significantly inhibits T-cell proliferation in vitro at clinically relevant concentrations. Ann Rheum Dis, 63(suppl):142.

Ndejembi MP, Patke DS, Bingaman AW, et al. 2005. CTLA4-Ig treatment promotes loss of antigen-activated effector memory CD4 T-cells. Arthritis Rheum, 52(Suppl):S492-3.

Ponchel F, Morgan AW, Bingham SJ, et al. 2002. Dysregulated lymphocyte proliferation and differentiation in patients with rheumatoid arthritis. Blood, 100:4550-6
Russell A, Emery P, Kafka SP, et al. 2005. Abatacept improves clinical responses regardless of baseline physical function: results from the AIM trial. Arthritis Rheum, 52:S543

Sakaguchi N, Takahashi T, Hata H, et al. 2003. Altered thymic T-cell selection due to a mutation of the ZAP-70 gene causes autoimmune arthritis in mice. Nature, 426:454-60.

Salazar-Fontana LI, Sanz E, Me'rida et al. 2001. Cell surface CD28 levels define four CD41 T cell subsets: abnormal expression in rheumatoid arthritis. Clin Imm, 99:253-65

Schiff M, Dougados M, Luggen M, et al. 2005. Abatacept leads to significant improvements in all American college of rheumatology core components in patients with an inadequate response to antiTNF therapy in the ATTAIN trial. Ann Rheum Dis, 64(Suppl III):435.

Symington FW, Brady W, Linsley PS. 1993. Expression and function of B7 on human epidermal langerhans cells. J Immunol, 150:128695.

Talamo J, Frater A, Gallivan S, et al. 1997. Use of the short form 36 (SF36) for health status measurement in rheumatoid arthritis. Br J Rheumatol, 36:463-9.

Tang Q, Boden EK, Henriksen KJ, et al. 2004. distinct roles of CTLA-4 and TGF-b in $\mathrm{CD}^{+} \mathrm{CD} 25^{+}$regulatory $\mathrm{T}$ cell function. Eur J Imm, 34:2996-3005.

Townsend RM, Kliwinski C, Kukral D, et al. 2005. Prophylactic administration of abatacept prevents disease induction and bone destruction in a rat model of collagen-induced arthritis. Ann Rheum Dis, 64(Suppl III):439.

Vincenti F, Larsen C, Durrbach A, et al. 2005. Costimulation blockade with belatacept in renal transplantation. $N$ Engl J Med, 353:770-81.

Weinblatt M, Combe B, White A, et al. 2005. Safety of abatacept in patients with active rheumatoid arthritis receiving background non-biologi and biologic DMARDs: 1 year results of the ASSURE trial. Ann Rheum Dis, 64(Suppl III):60.

Weisman M, Durez P, Hallegua D, et al. 2004. Abatacept (CTLA4; BMS-188667) inhibits T-cell activation and the subsequent activation of inflammatory cell types, as demonstrated by sustained reductions in multiple inflammatory biomarkers. Ann Rheum Dis, 63(Suppl I): 138 
